\title{
Gender differences in self-inflicted burns
}

\author{
Fidel-Kinori, S.G. ${ }^{1,2^{*}}$, Castellano-Tejedor, C. ${ }^{2,3}$, Cepeda Diez, M.C. ${ }^{1,2}$, Barret Nerin, J.P. ${ }^{1,2}$ \\ ${ }^{1}$ University Hospital Vall d'Hebron, Passeig Vall d'hebron 119-129, 08035, Barcelona (Spain) \\ ${ }^{2}$ Autonomous University of Barcelona, Campus UAB, 08193, Bellaterra (Spain) \\ ${ }^{3}$ RE-FiT Research Group, Intermediate Care Hospital Parc Sanitari Pere Virgili, Esteve Terrades 30, 08023, Barcelona (Spain)
} *sgfidel@gmail.com

\section{Introduction}

The risk of self-inflicted burns has been described as highly influenced by people's living conditions, lifestyles and culture [1]. These factors partly explain differences observed globally in rates and distribution of burnrelated self-inflicted injuries both between and within countries [1,2]. So far, little is known about gender differences on preferred methods for these types of injuries, motives, and also gender differences in different cultures. However, healthcare professionals and policy makers could benefit from this knowledge to design tailored effective preventive strategies [3, 4].

\section{Objectives}

- To analyse if gender-related patterns of self-inflicted burns exist.

- To describe prototypical profiles between genders.

\begin{tabular}{|c|c|}
\hline variable & frequency \\
\hline Type of SIB & $\begin{array}{l}\text { autolytic attempt ( } n=35,68,6 \%) \\
\text { pseudo autolytic attempt ( } n=16,31,4 \%)\end{array}$ \\
\hline Gender & males $(n=38,74,5 \%)$; females $(n=13,25,5 \%)$ \\
\hline Age & $42,16 \pm 13,24$ years \\
\hline Place of birth & Spain $(n=37,72,5 \%)$ \\
\hline Children & without children, $n=24,55,8 \%$ \\
\hline Civil status & single $(n=31,66 \%)$ \\
\hline Education level & elementary education $(n=38,84,4 \%)$ \\
\hline Job status & $\begin{array}{l}\text { unemployed }(n=29,64,5 \% \\
\text { retired }(n=1,2,2 \%) \\
\text { unable to work }(n=4,5,9 \%)\end{array}$ \\
\hline Triggers of the SIB & $\begin{array}{l}\text { psychopathology ( } n=20,48,8 \%) \\
\text { familial conflicts ( } n=14,34,1 \%) \\
\text { unresolved issues with justice ( } n=3,7,3 \%) \\
\text { problems at work ( } n=1,2,2 \%) \\
\text { other unspecified causes ( } n=2,4,9 \%)\end{array}$ \\
\hline Method of SIB & set fire on clothes $(n=42,82,4 \%)$ \\
\hline Place of SIB & $\begin{array}{l}\text { home }(n=27,55,1 \%) \\
\text { public places }(n=12,24,5 \%)\end{array}$ \\
\hline Psychopathology & $\begin{array}{l}\text { Past psychodiagnostic: } \\
\text { - } 90,2 \% \text { patients ( } n=46) \\
\text {-Active psychiatric treatment } 66,7 \%(n=34) \\
\text { Psychopathological diagnosis: } \\
\text {-bipolar disorder ( } n=12,25 \%) \\
\text {-major depression ( } n=11,22,9 \%) \\
\text { - schizophrenia ( } n=10,20,8 \%)\end{array}$ \\
\hline Previous attempts & range 0 and 6 (mean $1,67 \pm 1,57)$ \\
\hline TBA & $25,86 \% \pm 26,32$ \\
\hline LOS & $\begin{array}{l}\text { mean stage } 32,43 \pm 30,36 \text { days } \\
\text { (range } 1-123 \text { days) }\end{array}$ \\
\hline $\begin{array}{l}\text { Destination at } \\
\text { discharge }\end{array}$ & $\begin{array}{l}\text { at home ( } n=20,39,2 \%) \\
\text { to other acute units/hospitals ( } n=15,29,4 \%)\end{array}$ \\
\hline
\end{tabular}

\section{Methods}

This cross-sectional study is based on burn case reports $(\mathbf{N}=\mathbf{5 1})$ from an acute specialized burns unit (SBU) from a reference hospital in Catalonia, Spain (2010-2018, 1,45\% of all Burns Units income)

Data regarding socio-demographic, injury characteristics, and other relevant clinical variables were collected.

\section{Results}

Differences between genders were observed for the intention of the self-inflicted burn with significantly more males presenting these injuries as a clear autolytic attempt $\left(x^{2}=4,093, p=0.043\right)$.

\section{Conclusions}

Most patients with self-inflicted burns were men with clear autolytic intentions.

Considering the high prevalence of psychiatric

disorders among the sample (both genders

included), it cannot be concluded that they present

higher risk factors compare to females or use more

aggressive methods.

However, there is a clear need of constant

psychiatric support even once discharged is clear,

since it can be extremely helpful in preventing

future episodes of self-harm or suicide.

\section{References}

Peck MD. Epidemiology of burns throughout the World. Part II: Intentional burns in adults. Burns 2012;38(5):630-7

Laloë V. Patterns of deliberate self-burning in various parts of the world. A review. Burns 2004;30(3):207-15

- Titscher A, Lumenta DB, Belke LP, Kamolz LP, Frey M. A new diagnostic tool for the classification of patients with self-inflicted burns (SIB): The SIB-Typology and its implications for clinical practice. Burns 2009;35(5):733-4

Llamaran K, Malaiappan M, Kannan PP, Jagadeesan MS, Jose Mathew, Heber Anandan. Relationship between Psychosocial Stressors and the Intent and Lethality of Suicidal Behavior. Int J Scientif Study 2016,4(7)35-8 